\title{
Hubungan Asupan Cairan Ibu Hamil terhadap Indeks Cairan Amnion
}

\author{
Eni Fatmawati ${ }^{1}$, Diah Rumekti Hadiati ${ }^{2}$, Heru Pradjatmo ${ }^{3}$ \\ 1,2,3 Departemen Obstetri dan Ginekologi \\ Fakultas Kedokteran Universitas Gadjah Mada \\ Korespondensi: enidrog11@yahoo.com \\ Submisi:24 Februari 2016; Revisi: \\ ; Penerimaan:
}

\begin{abstract}
Background: Adequate amniotic fluid volume is a requirement for intra uterine fetal development and good pregnancy outputs / neonatal. Adequate intake of fluid in pregnant women can increase both the amniotic fluid index on oligohydramniotic or normoamniotic, but the scientific basis for the adequacy of the recommended daily fluid have not clear yet. Furthermore, the fluid intake counseling in addition to nutrition for pregnant women is needed.

Objective: To determine the fluid intake in pregnant women and the mean difference of amniotic fluid index on adequate fluid intake compared to less fluid intake.

Method: This research used prospective observational cohort study, conducted against the third semester pregnant women in Puskesmas Mergangsan and Tegalrejo Yogyakarta during July until September 2014. The subjects who met the inclusion criteria were divided into adequate and less fluid intake groups. The correlation between fluid intake and amniotic fluid index was analyzed using t-test and linear regression.

Result and Discussion: The total subjects who met the criteria were 27 people, consist of 12 people in adequate fluid intake group and 15 people in less fluid intake group. The mean of subject's fluid intake $2078 \mathrm{ml}$ (enough), while the mean of amniotic fluid index (AFI) $12,76 \mathrm{~cm}$ (normoamniotic). The result showed that there was a significant difference $(3,50 \mathrm{~cm}$ (IK $95 \% ; 1,5-5,48) ; \mathrm{P}<0,05)$ between the mean of AFI from adequate fluid intake group compared to less fluid intake group. Simple linear regression test showed the effect of fluid intake for AFI namely 31,7\%; with the amount of predicted $\mathrm{AFI}=10,686+3,545 \mathrm{x}$ fluid intake $-1,015 \mathrm{x}$ age $-1,317 \mathrm{x}$ education $+0,314 \mathrm{x}$ occupation $(\mathrm{ARS}=44,5 \%)$. External variables (age, education, and occupation) had no significant effect for AFI .

Conclusion: The mean preview of fluid intake in the third semester pregnant women in Yogyakarta was adequate. Moreover, there was a AFI signifficant difference between adequate fluid intake compared to less fluid intake.
\end{abstract}

Keywords: fluid intake, amniotic fluid index, AFI

\section{ABSTRAK}

Latar belakang: Volume cairan amnion yang adekuat adalah syarat untuk perkembangan janin intra uteri dan keluaran kehamilan/ neonatus yang baik. Kecukupan asupan cairan ibu hamil dapat meningkatkan indeks cairan amnion baik pada oligohidramnion maupun normoamnion, tetapi dasar ilmiah bagi kecukupan harian cairan yang dianjurkan belum jelas. Pentingnya konseling asupan cairan selain asupan nutrisi kepada ibu hamil.

Tujuan: Memperoleh gambaran asupan cairan pada ibu hamil dan mengetahui perbedaan rerata indeks cairan amnion pada asupan cairan cukup dibandingkan asupan cairan kurang.

Metode: Penelitian ini menggunakan studi observasional kohort prospektif, dilakukan pada ibu hamil trimester tiga di Puskesmas Mergangsan dan Tegalrejo Yogyakarta pada bulan Juli s.d September 2014. Subyek penelitian yang memenuhi kriteria inklusi dibagi dalam kelompok asupan cairan cukup dan kurang. Hubungan antara asupan cairan dan indeks cairan amnion dianalisis dengan $t$ test dan regresi linear.

Hasil dan Pembahasan: Subyek penelitian yang memenuhi kriteria sebanyak 27 orang terdiri dari 12 orang kelompok asupan cairan cukup dan 15 orang asupan cairan kurang. Nilai rerata asupan cairan subyek $2078 \mathrm{ml}$ (cukup), nilai rerata AFI 12,76 cm (normoamnion). Didapatkan perbedaan bermakna secara statistik rerata AFI kelompok asupan cairan cukup dibandingkan asupan cairan kurang sebesar 3,50 cm (IK 95\%; 1,5-5,48); P< 0,05. Test regresi linear sederhana menunjukkan pengaruh asupan cairan terhadap AFI sebesar 31,7\%; dengan perkiraan besarnya AFI = 7,710 $+3,493 \times$ asupan cairan (ARS $=31,7 \%$ ). Test regresi linear ganda, pengaruh asupan cairan terhadap AFI sebasar $44,5 \%$ dengan perkiraan besarnya AFI $=10,686$ $+3,545 \times$ asupan cairan $-1,015 \times$ umur $-1,317 \times$ pendidikan $+0,314 \times$ pekerjaan ( $A R S=44,5 \%$ ). Variabel luar (umur, pendidikan, dan pekerjaan) tidak mempunyai pengaruh bermakna terhadap AFI.

Kesimpulan: Gambaran rerata asupan cairan ibu hamil trimester tiga di Yogyakarta adalah cukup dan didapatkan perbedaan bermakna AFI ibu hamil asupan cairan cukup dibanding asupan cairan kurang.

Kata kunci: Asupan cairan, indeks cairan amnion, AFI 


\section{PENDAHULUAN}

Air merupakan komponen terbesar tubuh kita, yaitu sekitar $60 \%$ berat badan. Komposisi cairan tubuh terdiri dari cairan intraseluler $65 \%$ dan cairan ekstraseluler yang terdiri dari cairan interstisial dan plasma sebesar $35 \% .{ }^{1}$ Air harus diperoleh dari makanan dan minuman setiap hari karena air yang dihasilkan dari metabolisme tubuh saja tidak cukup. ${ }^{2}$ Asupan cairan yang kurang berhubungan dengan beberapa masalah kesehatan, meskipun demikian, air sering diabaikan sebagai komponen dari diet. Dekade terakhir ini, perhatian publik tertuju pada pentingnya hidrasi yang cukup, tetapi dasar ilmiah bagi kecukupan harian cairan yang dianjurkan belum jelas. ${ }^{1,3}$

Kehamilan cukup bulan menyebabkan peningkatan berat badan sekitar $12,5 \mathrm{~kg}$, sebagian besar terdiri dari air, sehingga total cairan tubuh meningkat 6-8 liter, yang terdapat di cairan amnion, plasenta dan cairan ekstraseluler dan intraseluler. Volume plasma maternal akan meningkat $40-45 \%$, menyebabkan penurunan osmolalitas plasma 10 mosm/kg air, dari 290 menjadi 280 mosm/kg air. Nilai ambang osmolalitas plasma terhadap rasa haus dan sekresi hormon antidiuretik menurun, terjadi pada awal kehamilan kemudian konstan pada kehamilan lanjut, menyebabkan peningkatan retensi cairan, hal ini dibutuhkan ibu untuk mempertahankan keseimbangan cairan tubuh. Kebutuhan cairan sangat tergantung terhadap asupan energi dari makanan, yaitu 1-1.5 ml cairan untuk setiap kilogram kalori asupan energi. Kebutuhan energi saat kehamilan rata-rata meningkat $300 \mathrm{kkal} / \mathrm{hari}$, oleh karena itu ibu hamil memerlukan setidaknya $300 \mathrm{ml}$ asupan air tambahan. Pada umumnya ibu hamil dianjurkan untuk minum minimal 8-10 gelas air setiap harinya. ${ }^{2,4,5}$ Volume cairan amnion yang adekuat adalah syarat untuk perkembangan janin intra uteri dan keluaran neonatus yang baik. ${ }^{6}$ Perkiraan volume cairan amnion dengan menggunakan sonografi merupakan pemeriksaan yang paling sensitif dan komponen penting untuk menilai profil biofisik janin. ${ }^{7}$ Beberapa studi telah mempelajari hubungan antara volume intravaskular ibu dan volume cairan amnion. Kilpatrick et al. dan Kilpatrick dan Safford melaporkan bahwa hidrasi air pada ibu meningkatkan indeks cairan amnion baik pada oligohidramnion maupun normoamnion. Fait et al. menunjukkan bahwa $75 \%$ ibu oligohidramnion yang mengkonsumsi air dua liter per hari, memperlihatkan peningkatan indeks cairan amnion sebesar $50 \%$. Mekanismenya masih belum jelas, mungkin berhubungan dengan perbaikan perfusi uteroplasenta atau perubahan osmolalitas plasma ibu dan janin, yang meningkatkan aliran urin janin. Oosterhof et al. menunjukkan peningkatan asupan air pada ibu hamil oligohidramnion akan meningkatkan aliran darah ke uterus dan plasenta, meningkatkan produksi urin janin sehingga meningkatkan valume cairan amnion. ${ }^{5,6,7}$

\section{METODE}

Penelitian ini merupakan studi observasional kohort prospektif dilakukan pada ibu hamil trimester tiga di Puskesmas Mergangsan dan Tegalrejo Yogyakarta pada bulan Juli s.d September 2014. Kriteria inklusi meliputi ibu hamil $\geq 29$ minggu, umur 2035 tahun, bersedia mengikuti penelitian dengan cara menandatangani informed consent, tinggal di Yogyakarta minimum 1 tahun terakhir, status ekonomi menengah, tampak sehat, hamil janin tunggal, selaput ketuban intak, tidak ada komplikasi kehamilan (hipertensi, diabetes). Kriteria eksklusi adalah subyek yang sulit berkomunikasi secara langsung atau buta huruf, sulit dilakukan pengukuran antropometri, tidak kooperatif dalam setiap pemeriksaan, sedang mengkonsumsi obat-obatan (seperti diuretik dan antihipertensi), serta sedang sakit.

Nilai kesalahan tipe I ditetapkan sebesar 5\% hipotesis satu arah dan kesalahan tipe II sebesar $10 \%$. Pengambilan data asupan cairan pada ibu hamil sudah dilaksanakan pada bulan Januari-Agustus 2014 sebagai bagian dari penelitian multisenter yang berjudul "Fluid and Nutrients Intake Study of Indonesian Pregnant and Lactating Woman in Jakarta, Yogakarta and Surabaya 2014" (FIS-PnL). Pengambilan data asupan cairan dan pengukuran indeks cairan amnion selanjutnya dilakukan pada bulan Juli - September 2014 dengan cara wawancara kuesioner dan observasi. Data asupan cairan diperoleh dengan cara observasi dan wawancara, dengan cara pencatatan cairan yang 
dikonsumsi subyek selama 7 hari. Setiap hari subyek dikunjungi ke rumah untuk mengumpulkan catatan asupan cairan hari sebelumnya dan menyediakan catatan yang baru untuk hari berikutnya. Subyek diberikan gelas minum yang sudah diketahui ukuran volumenya, untuk menentukan perkiraan volume cairan yang diminum. Asupan cairan dibagi 2 kategori; asupan cairan cukup (> $2000 \mathrm{ml}$ ) dan asupan cairan kurang ( $\leq 2000 \mathrm{ml}$ ). Pengukuran indeks cairan amnion, langsung dilakukan dengan ultrasonografi aloka dalam 24 jam setelah pencatatan asupan cairan. Dua pengukuran subyek pertama dikonfirmasikan hasilnya dengan dokter spesialis radiologi. Perbedaan pengukuran 1-2 cm kita anggap sama (tidak berbeda bermakna). ${ }^{9}$ Nilai normal AFI adalah $5-24 \mathrm{~cm}$, dibawahnya disebut oligohidramnion dan diatasnya disebut polihidramnion. ${ }^{10}$
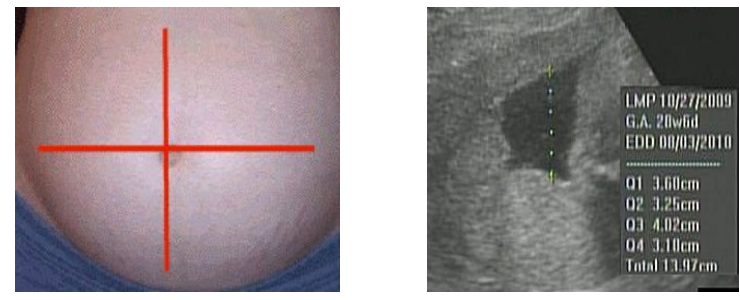

Gambar 1. Cara pengukuran indeks cairan amnion (AFI). Perut dibagi menjadi 4 kuadran (a), diameter terbesar pada kuadran (b) (Phelan dkk, 1987)

Data diolah menggunakan program komputer Microsoft Office Excell 2010 for Windows dan SPSS 22 for Windows. Analisis univariat untuk mengetahui karakteristik subyek penelitian dan melihat komparabilitas antar kelompok, dengan menghitung distribusi, frekuensi, rerata dan proporsi pada masingmasing variabel. Analisis bivariat untuk mengetahui hubungan antara dua variabel yang meliputi variabel bebas dengan variabel tergantung dan variabel luar dengan variabel tergantung tanpa pengendalian. Perbedaan rerata dianalisis dengan independent $t$-test sedangkan perbedaan proporsi dengan chi-square test. Analisis multivariat dengan analisis regresi linear sederhana dan regresi linear ganda, untuk mengetahui hubungan antar variabel bebas dan variabel tergantung secara bersama-sama dengan mengendalikan variabel luar. Variabel luar dengan $\mathrm{P}$ $<0,25$ diikutkan dalam analisis regresi linear ganda. Analisis statistic dianggap bermakna apabila $\mathrm{P}<0,05$.

\section{HASIL DAN PEMBAHASAN}

Total populasi 37 ibu hamil di Puskesmas Mergangsan dan Tegalrejo pada bulan Juli sd September 2014, tereksklusi 10 orang, yang memenuhi kriteria inklusi 27 orang terdiri dari 12 orang asupan cairan cukup dan 15 orang asupan cairan kurang.

Karakteristik subjek penelitian ditampilkan pada Tabel 1. Komparabilitas variabel umur, IMT, paritas, umur kehamilan, pendidikan dan pekerjaan antara kelompok subyek dengan asupan cairan cukup dan kelompok subyek dengan asupan cairan kurang tidak ada perbedaan bermakna $(P>0,05)$.. Tabel 2 menunjukkan rerata asupan cairan subyek adalah $2078 \mathrm{ml}$ (cukup) dan rerata $\mathrm{AFI}$ 12,76 cm, $\mathrm{AFI}$ minimum 7,3 cm dan $\mathrm{AFI}$ maksimum $18,9 \mathrm{~cm}$ disebut normoamnion.

Tabel 1. Karakteristik subjek penelitian

\begin{tabular}{|c|c|c|c|c|c|}
\hline \multirow{3}{*}{$\begin{array}{c}\text { Karakteristik } \\
\text { subyek }\end{array}$} & \multicolumn{4}{|c|}{ Asupan cairan } & \multirow{3}{*}{$P$} \\
\hline & \multicolumn{2}{|c|}{ Cukup } & \multicolumn{2}{|c|}{ Kurang } & \\
\hline & $\mathrm{n}$ & $\%$ & $\mathrm{n}$ & $\%$ & \\
\hline \multicolumn{6}{|l|}{ Umur } \\
\hline - 20-29 tahun & 8 & 66,7 & 8 & 53,3 & 0,484 \\
\hline - 30-35 tahun & 4 & 33,3 & 7 & 46,7 & \\
\hline \multicolumn{6}{|l|}{ IMT } \\
\hline - Normal & 4 & 33,3 & 7 & 46,7 & 0,484 \\
\hline - Gemuk & 8 & 66,7 & 8 & 53,3 & \\
\hline \multicolumn{6}{|l|}{ Paritas } \\
\hline - Nulipara & 6 & 50,0 & 7 & 46,7 & 0,884 \\
\hline - Primipara & 3 & 25,0 & 5 & 33,3 & \\
\hline - Multipara & 3 & 25,0 & 3 & 20,0 & \\
\hline \multicolumn{6}{|l|}{ Umur kehamilan } \\
\hline - Kurang bulan & 11 & 91,7 & 12 & 80,0 & 0,396 \\
\hline - Cukup bulan & 1 & 8,3 & 3 & 20,0 & \\
\hline \multicolumn{6}{|l|}{ Pendidikan } \\
\hline - Rendah & 1 & 8,3 & 2 & 13,3 & 0,583 \\
\hline - Menengah & 3 & 25,0 & 6 & 40,0 & \\
\hline - Tinggi & 8 & 66,7 & 7 & 46,7 & \\
\hline \multicolumn{6}{|l|}{ Pekerjaan } \\
\hline - Pedagang & 0 & 0 & 1 & 6,7 & 0,190 \\
\hline - Karyawan/PNS & 4 & 33,3 & 9 & 60,0 & \\
\hline - IRT & 8 & 66,7 & 5 & 33,3 & \\
\hline
\end{tabular}


Tabel 2. Gambaran asupan cairan dan nilai indeks cairan amnion

\begin{tabular}{lcc}
\hline & Asupan cairan $(\mathrm{ml})$ & AFI $(\mathrm{cm})$ \\
\hline $\mathrm{N}$ & 27 & \\
Rerata & 2078,15 & 12,76 \\
Median & 1921,43 & 12,80 \\
SD & 680,18 & 3,02 \\
Minimum & 807,29 & 7,30 \\
Maksimum & 4421,43 & 18,90 \\
p25 & 1714,29 & 11,00 \\
p50 & 1921,43 & 12,80 \\
p75 & 2350,00 & 14,60 \\
\hline
\end{tabular}

Hubungan antara asupan cairan dengan indeks cairan amnion ditunjukkan tabel 3, didapatkan perbedaan yang bermakna secara statistik rerata AFI kelompokibu hamil asupan cairan cukup dibandingkan asupan cairan kurang sebesar 3,50 cm (IK 95\%; 1,50$5,48) ; P<0,05$. Hubungan antara umur, indeks massa tubuh, paritas, umur kehamilan, dan pendidikan terhadap indeks cairan amnion ditunjukkan pada table 4 , hasilnya tidak didapatkan perbedaan yang bermakna $(P>0,05)$, sedangkan hubungan antara pekerjaan terhadap indeks cairan amnion didapatkan perbedaan yang bermakna $(P<0,05)$.

Tabel 3. Hubungan asupan cairan dengan indeks cairan amnion

\begin{tabular}{|c|c|c|c|c|c|c|}
\hline \multirow{2}{*}{ Variabel } & \multirow{2}{*}{$\mathrm{N}$} & \multicolumn{2}{|c|}{$\mathrm{AFI}(\mathrm{cm})$} & \multirow{2}{*}{$\begin{array}{l}\triangle \mathrm{AFI} \\
(\mathrm{cm})\end{array}$} & \multirow{2}{*}{ IK 95\% } & \multirow{2}{*}{$P$} \\
\hline & & Rerata & SD & & & \\
\hline $\begin{array}{l}\text { Asupan } \\
\text { cairan } \\
\text { cukup }\end{array}$ & 12 & 14,70 & 2,66 & 3,50 & $1,50-5,48$ & 0,001 \\
\hline $\begin{array}{l}\text { Asupan } \\
\text { cairan } \\
\text { kurang }\end{array}$ & 15 & 11,20 & 2,36 & & & \\
\hline
\end{tabular}

$\Delta \mathrm{AFI}=$ perbedaan rerata $\mathrm{AFI}$ antara asupan cairan cukup dan asupan cairan kurang.
Tabel 4. Hubungan variabel umur, indeks massa tubuh, paritas, umur kehamilan, pendidikan dan pekerjaan terhadap indeks cairan amnion

\begin{tabular}{lrrrr}
\hline \multirow{2}{*}{ Variabel } & & \multicolumn{2}{c}{ AFI (cm) } & \multirow{2}{*}{ N } \\
\cline { 3 - 4 } & & Rerata & \multicolumn{1}{c}{ SD } & \\
\hline Umur (tahun) & & & & \\
- 20-29 tahun & 16 & 13,55 & 2,66 & 0,098 \\
- 30-35 tahun & 11 & 11,59 & 3,26 & \\
\hline IMT & & & & \\
- Normal & 11 & 13,35 & 3,16 & 0,410 \\
- Gemuk & 16 & 12,35 & 2,95 & \\
\hline Paritas & & & & \\
- Nulipara & 13 & 12,87 & 2,39 & 0,937 \\
- Primipara & 8 & 12,43 & 3,93 & \\
- Multipara & 6 & 12,95 & 3,43 & \\
\hline Umur kehamilan & & & & \\
- Kurang bulan & 23 & 12,97 & 3,12 & 0,403 \\
- Cukup bulan & 4 & 11,54 & 2,30 & \\
\hline Pendidikan & & & & \\
- Rendah & 3 & 13,83 & 0,67 & 0,147 \\
- Menengah & 9 & 14,09 & 2,99 & \\
- Tinggi & 15 & 11,74 & 3,04 & \\
\hline Pekerjaan & & & & \\
- Pedagang & 1 & 7,40 & 2,84 & 0,022 \\
- Karyawan/PNS & 13 & 11,80 & 2,51 & \\
- IRT & 13 & 14,11 & 3,02 & \\
\hline
\end{tabular}

Hasil uji multivariat ditunjukkan table 5, model 1 diketahui bahwa terdapat pengaruh asupan cairan terhadap indeks cairan amnion $(P<0,05)$ dengan besarnya pengaruh sebesar $31,7 \%$. Model 1 dapat dibuat persamaan; indeks cairan amnion $=7,710+$ $3,493 \times$ asupan cairan (ARS $=31,7 \%$ ). Pada model 2 ditambahkan variabel luar yaitu umur, pendidikan dan pekerjaan, diketahui bahwa asupan cairan mempunyai pengaruh signifikan terhadap indeks cairan amnion $(P<0,05)$, dengan pengaruh sebesar $44,5 \%$, sedangkan umur, pendidikan dan pekerjaan tidak mempunyai pengaruh signifikan terhadap indeks cairan amnion $(P>0,05)$. Model 2 dapat dibuat persamaan; indeks cairan amnion $=10,686$ $+3,545 \mathrm{x}$ asupan cairan $-1,015 \mathrm{x}$ umur $-1,317 \mathrm{x}$ pendidikan $+0,314 \times$ pekerjaan (ARS $=44,5 \%$ ). Variabel asupan cairan, umur, pendidikan dan pekerjaan secara simultan mempunyai pengaruh signifikan terhadap indeks cairan amnion $(P<0,05)$. 
Tabel 5. Hubungan asupan cairan dan variabel luar dengan indeks cairan amnion

\begin{tabular}{lcccc}
\hline \multirow{2}{*}{ Variabel } & \multicolumn{4}{c}{ AFI } \\
\cline { 2 - 5 } & \multicolumn{2}{c}{ Model 1 } & \multicolumn{2}{c}{ Model 2 } \\
\cline { 2 - 5 } & $\mathrm{b}$ & $P$ & $\mathrm{~B}$ & $P$ \\
\hline Asupan cairan & 3,493 & 0,001 & 3,545 & 0,003 \\
Umur & & & $-1,015$ & 0,278 \\
Pendidikan & & & $-1,317$ & 0,109 \\
Pekerjaan & & & 0,314 & 0,558 \\
\multicolumn{1}{c}{ ARS } & \multirow{2}{*}{ P } & & \multicolumn{2}{c}{0,445} \\
\end{tabular}

$\mathrm{b}=$ koefisien regresi;

sesuai dengan persamaan, $Y=a+b X($ model 1$)$;

$Y=a+b_{1} X_{1}-b_{2} X_{2}-b_{3} X_{3}+b_{4} X_{4}$ (model 2);

$a=$ konstanta (nilai $Y$ apabila $X=0$ );

ARS (adjusted $\mathrm{R}$ square) = koefisien determinasi

Karakteristik subyek asupan cairan cukup maupun asupan cairan kurang; umur, indeks massa tubuh, paritas, umur kehamilan, pendidikan dan pekerjaan terhadap asupan cairan pada penelitian ini adalah sama / homogen $(P>0,05)$.

Umur berpengaruh terhadap kebutuhan cairan tubuh, semakin tinggi umur seseorang semakin banyak air yang dibutuhkan oleh tubuh untuk melakukan metabolisme dan aktivitas yang dilakukan oleh tubuh. ${ }^{13}$ Hubungan umur terhadap asupan cairan dan hubungan umur terhadap indeks cairan amnion menunjukkan hasil yang tidak bermakna $(P>0,05)$. Berbeda dengan studi Vico et al., yang menemukan bahwa semakin tinggi umur menyebabkan perubahan angiosklerotik pembuluh darah uterus yang menyebabkan penurunan aliran arteri uterin dan penurunan perfusi uteroplasenta, pada akhirnya menimbulkan penurunan volume cairan amnion. ${ }^{11,12}$

Hubungan IMT terhadap asupan cairan tidak menunjukkan hubungan yang bermakna $(P>0,05)$, berbeda dengan penelitian Santoso et al. Yang menemukan bahwa kandungan air didalam sel lemak lebih rendah dari pada kandungan air dalam sel otot sehingga kebutuhan cairan orang obesitas lebih tinggi dari pada orang yang tidak obesitas, oleh karena itu orang obesitas lebih mudah kekurangan air. Hubungan umur kehamilan terhadap asupan cairan tidak menunjukkan hubungan bermakna $(P>0,05)$, karena variabel umur kehamilan sudah dikontrol, yang memenuhi inklusi adalah trimester 3 ( $\geq 29$ minggu).

Paritas semakin tinggi menyebabkan kelainan dinding pembuluh darah endometrium berupa angiosklerotik yang menyebabkan gangguan sirkulasi uteroplasenta. ${ }^{11,16}$ Sirkulasi uteroplasenta mempengaruhi regulasi volume cairan amnion. ${ }^{12}$ Pada penelitian ini hubungan paritas terhadap indeks cairan amnion tidak bermakna $(P>0,05)$.

Hubungan pekerjaan terhadap asupan cairan pada penelitian ini tidak bermakna $(P>0,05)$, tapi hasil analisis bivariat pekerjaan terhadap indeks cairan amnion menunjukkan hubungan yang signifikan $(P<0,05)$. Berbeda dengan penelitian Kaur et al. menyatakan bahwa asupan cairan ibu hamil di rumah (IRT) biasanya lebih tinggi dari pada ibu hamil yang bekerja atau berada di tempat lain. ${ }^{14}$ Pendidikan menurut Notoatmodjo bertujuan untuk mengubah perilaku seseorang ke arah yang menguntungkan atau yang seharusnya dalam hal ini perilaku minum yang sesuai dengan yang dianjurkan, juga mempengaruhi pengetahuan, sikap dan perilaku seseorang yang dapat mempengaruhi asupan cairannya. Hubungan pendidikan terhadap asupan cairan tidak menunjukkan hubungan yang bermakna $(P>0,05)$, berbeda dengan hasil penelitian Kant et al. yang melihat adanya hubungan yang bermakna antara tingkat pendidikan dan total asupan cairan.

Hasil dari penelitian ini membuktikan bahwa asupan cairan ibu hamil yang cukup dibandingkan asupan cairan yang kurang menyebabkan perbedaan indeks cairan amnion secara bermakna, perbedaan AFI sebesar 3,50 (IK 95\%; 1,87-4,80); P < 0,05. Hasil tersebut sesuai dengan hasil penelitian Borges et al. yang mendemonstrasikan peningkatan AFI secara signifikan 10 kali lipat pada ibu hamil normoamnion yang diberikan hidrasi $1,5 \mathrm{~L}$ cairan isotonis yang diminum selama 2-4 jam, dan peningkatan AFI 4 kali lipat pada hidrasi 1,5 L air minum. ${ }^{15}$

Hasil uji variabel-variabel luar terhadap indeks cairan amnion, tidak mempunyai pengaruh bermakna terhadap indeks cairan amnion ( $P>$ $0,05)$, kecuali variabel pekerjaan $(P<0,05)$. Hasil uji multivariat model 1 diketahui bahwa terdapat pengaruh asupan cairan terhadap indeks cairan amnion $(P<0,05)$ dengan besarnya pengaruh 
sebesar 31,7\% sedangkan sisanya 68,3\% lainnya dipengaruhi oleh faktor-faktor lain. Model 1 dapat dibuat persamaan; indeks cairan amnion $=7,710+$ $3,493 \times$ asupan cairan (ARS $=31,7 \%$ ). Pada model 2 ditambahkan variabel luar yaitu umur, pendidikan dan pekerjaan, diketahui bahwa asupan cairan mempunyai pengaruh signifikan terhadap indeks cairan amnion $(P<0,05)$, dengan pengaruh sebesar $44,5 \%$, sedangkan umur, pendidikan dan pekerjaan tidak mempunyai pengaruh signifikan terhadap indeks cairan amnion $(P>0,05)$. Model 2 dapat dibuat persamaan; indeks cairan amnion $=10,686$ $+3,545 \times$ asupan cairan $-1,015$ x umur $-1,317 \times$ pendidikan $+0,314 \times$ pekerjaan $($ ARS $=44,5 \%)$.

Hidrasi ibu hamil bisa meningkatkan indeks cairan amnion berhubungan dengan peningkatan kecepatan rata-rata arteri uterina tetapi mekanisme perubahan dan berapa lama waktu untuk meningkatkan AFI belum diketahui secara jelas. Beall dan Cunningham et al. menyatakan bahwa pada kehamilan trimester 2-3, sumber utama cairan amnion adalah produksi urin janin. Pada orang dewasa, diuresis berkorelasi secara langsung dengan osmolalitas dan volume intravaskular. Data klinik menyatakan bahwa janin dapat merespon perubahan osmolalitas dan volume intravaskular maternal; produksi urin janin berubah dengan perubahan osmolalitas maternal. Studi Battaglia et al. menyatakan bahwa pemberian cairan intravena pada ibu hamil berpengaruh secara bermakna terhadap perubahan tekanan osmotik total plasma janin. ${ }^{17}$ Studi Stevens dan Lumbers, menyatakan bahwa jika asupan cairan kambing hamil dikurangi, menyebabkan perubahan cairan tubuh janin dan menyebabkan urin janin lebih pekat. Pada studi ini meskipun volume intravaskular dan osmolalitas ibu hamil tidak diukur, kita percaya bahwa peningkatan indeks cairan amnion dipengaruhi oleh asupan cairan ibu yang menyebabkan peningkatan volume dan penurunan osmolalitas intravaskular. ${ }^{18}$

Volume cairan amnion yang adekuat merupakan syarat meningkatnya keluaran kehamilan / perinatal. Hasil penelitian ini membuktikan bahwa asupan cairan berpengaruh secara bermakna terhadap peningkatan indeks cairan amnion, sehingga disimpulkan asupan cairan cukup atau peningkatan asupan cairan diperlukan agar keluaran perinatal / kehamilan meningkat. Komunikasi, informasi dan edukasi tentang asupan cairan atau hidrasi ibu hamil perlu diberikan, selain kebutuhan gizi atau nutrisi ibu hamil.

Pada penelitian ini banyak ditemukan kelemahan-kelamahan, antara lain: 1) tidak diketahui latar belakang status hidrasi subyek penelitian secara obyektif, hanya berdasarkan gambaran klinis; 2 ) tidak dilakukan pengukuran indeks cairan amnion awal sebelum dilakukan observasi asupan cairan tujuh hari; 3) Proporsi jumlah sampel tidak seimbang, kelompok asupan cairan cukup $(n=12)$ sedangkan kelompok asupan cairan kurang $(n=15)$. Hal ini disebabkan karena keterbatasan jumlah sampel, dan asupan cairan subyek tidak bisa dikontrol peneliti. Berdasarkan hasil uji beda proporsi antara kedua kelompok subyek tidak berbeda secara bermakna $(P>0,05)$. Kita menyadari dibutuhkan penelitian lebih lanjut untuk konfirmasi data kami, tentang asupan cairan ibu hamil, cara meningkatkan indeks cairan amnion tanpa meningkatkan komplikasi ibu dan janin, dan faktor-faktor yang mempengaruhi hubungan tersebut, dengan tujuan utama meningkatkan keluaran kehamilan / perinatal, misalnya pendekatan untuk mengatasi komplikasi oligohidramnion,. Hidrasi cairan / asupan cairan merupakan metode yang murah, sederhana dan tidak invasif.

\section{KESIMPULAN DAN SARAN}

Gambaran rerata asupan cairan ibu hamil trimester tiga di Yogyakarta adalah cukup ( $2078 \mathrm{ml} /$ hari).

Ada perbedaan bermakna indeks cairan amnion ibu hamil dengan asupan cairan cukup dibanding asupan cairan kurang.

Disarankan komunikasi, informasi dan edukasi ibu hamil tentang pentingnya hidrasi/asupan cairan selain gizi/nutrisi pada asupan makanan, karena berhubungan dengan peningkatan indeks cairan amnion untuk meningkatkan keluaran kehamilan/ perinatal.

Diperlukan penelitian lebih lanjut tentang pengaruh asupan cairan dan faktor-faktor lain (misalnya umur, pendidikan, pekerjaan) terhadap 
indeks cairan amnion dengan metode RCT, sehingga pengelompokan subyek bisa dikontrol peneliti, tidak terjadi secara alami.

\section{DAFTAR PUSTAKA}

1. Sawka MN, Cheuvront SN, Carter R. 2005. Human water needs. Nutrition Reviews, 63(6): S30-S39.

2. Montgomery KS. 2002. An update on water needs during pregnancy and beyond. The Journal of Perinatal Education, 11(3): 40-42.

3. Jequier E, Constant F. 2010. Water as an essential nutrient: the physiological basis of hydration. European Journal of Clinical Nutrition, 2010, 64: 115123.

4. EFSA. 2010. Panel on dietetic products nutritions and allergies: Scientific opinion on dietary reference values for water. European Food Safety Authority Journal, 2010, 8(3): 1459. Available online: http:// www.efsa.europa.eu/en/efsajournal/pub/1459.html.

5. Konsensus Nasional POGI. 2013. Kebutuhan asupan air bagi ibu hamil, melahirkan dan menyusui.

6. Patrelli TS, Gizzo S, Cosmi E, Carpano MG, Gangi SD, Pedrazzi G, dkk. 2012. Maternal hydration therapy improves the quantity of amniotic fluid and the pregnancy outcome in third-trimester isolated oligohydramnios: A controlled randomized institutional trial. J Ultrasound Med, 31: 239-244.

7. Moore TR. 2011. The role of amniotic fluid assessment in evaluating fetal well-being. clin perinatologi, 38: 33-46.

8. Borges VTM, Rososchansky J, Abbade JF, Dias A, Peracoli JC, Rudge MVC. 2011. Effect of maternal hydration on the increase of amniotic fluid index, Braz J Med Biol Res, 44(3): 263-266.
9. Rutherford SE, Smith CV, Phelan JP, Kawakami K, Ahn MO. 1987. Four-quadrant assessment of amniotic fluid volume interobserver and intraobserver. The Journal of reproductive Medicine, 32(8): 587-589.

10. Hinh ND, Ladinsky JL. 2005. Amniotic fluid index measurements in normal pregnancy after 28 gestational weeks. Internationan Journal of Gynecology \& Obstetrics, 91: 132-136.

11. Vico AE, Liu IKM, Brosnan RJ. 2016. Effects of estradiol on uterine perfusion in anesthetized cyclic mares affected with uterine vascular elastosis. Animal Reproductive Science, 164: 57-63.

12. Ross MG, Beall MH. 2014. Amniotic fluid dynamics. Maternal Fetal medicine. $7^{\text {th }}$ ed. 2014, Philadelphia. Elsevier saunders, 47-52.

13. Gustam. 2012. Faktor risiko dehidrasi pada remaja dan dewasa. Skripsi Sarjana Departemen Gizi Masyarakat Fakultas Ekologi Manusia IPB, Bogor.

14. Kaur S, Nieuwenhuijsen MJ, Ferrier H, Steer P. 2014. Exposure of pregnant women to tap water related activities. Occup Environ Med, 61: 454-460.

15. Borges VTM, Rososchansky J, Abbade JF, Dias A, Peracoli JC, Rudge MVC. 2011. Effect of maternal hydration on the increase of amniotic fluid index, Braz J Med Biol Res, 44(3): 263-266.

16. Gruninger B, Schoon HA, Klug E. 1998. Incidence and morphology of endometrial angiopathies in mares in relationship to age and parity. Journal of Comparative pathology, 119(3): 293-309.

17. Battaglia F, Prystowsky H, Smisson C, Hellegers A, Bruns P. 1960. Fetal blood studies: XIII. The effect of the administration of fluids intravenously to mothers upon the concentrations of water and electrolytes in plasma of human fetuses. Pediatrics, 25(2): 2-10.

18. Stevens AD, Lumbers ER. The effect of maternal fluid intake on the volume and composition of fetal urine. J Dev Physiol, 7: 161-166. 